\title{
Crianças e adolescentes com deficiência em situação de violência: cruzamento de conectores sociais
}

Disabled children and adolescents in situations of violence: crossing of social connectors

\section{Niños, niñas y adolescentes discapacitados en situaciones de violencia: cruze de conectores sociales}

\section{Laura Ceretta Moreira}

Professora doutora da Universidade Federal do Paraná, Curitiba, PR, Brasil

E-mail: laurac.moreira@gmail.com ORCID: https://orcid.org/0000-0003-4569-7369

Fabiola Rodrigues Del Mouro

Mestra pela Universidade Federal do Paraná, Curitiba, PR, Brasil

E-mail: frodriguesmouro@gmail.com ORCID: https://orcid.org/0000-0002-9437-9490

Recebido em 30 de setembro de 2021

Aprovado em 22 de dezembro de 2021

Publicado em 27 de dezembro de 2021

\section{RESUMO}

O artigo objetiva discutir as vulnerabilidades e exclusões vivenciadas por crianças e adolescentes com deficiência, assim como analisar as condições dessa população no que se refere às situações de violência, sobretudo, a intrafamiliar. Sendo assim, deficiência e violência, e seus conectores sociais, são focos deste artigo. O estudo se apoia na abordagem qualitativa com perspectiva descritivo-analítica, recorrendo às fontes documentais constantes em sítios públicos, censos educacionais e relatórios institucionais das secretarias municipais de assistência social dos municípios em estudo; esses últimos dados, por sua vez, caracterizam-se como fontes primárias de pesquisa. O lócus de análise ocorreu em dois municípios paranaenses, pertencentes à região metropolitana de Curitiba/PR, entre os anos de 2015 e 2021. Os dados mapearam situações de agressões e maus-tratos, e permitiram a análise cruzada das categorias: situação econômica das famílias e gênero. Dentre os resultados encontrados, destacam-se: a relação entre as precárias condições socioeconômicas das famílias e a deficiência; o quanto as crianças e adolescentes com deficiência experimentam taxas mais altas de violência, se comparadas com seus pares sem deficiência; quanto à questão de gênero, o município $A$ revelou que $79,66 \%$ da violência se deu para o gênero feminino, já o munícipio B observou-se que $75 \%$ dos casos de violência foram contra o gênero masculino. As conclusões apontam para a necessidade do adensamento de estudos sobre deficiência e violência com relação a outros conectores sociais; a importância da ampliação da rede de apoio às famílias e da formação qualificada de profissionais da saúde e da educação, enquanto política pública.

Palavras-chave: Criança e adolescente; deficiência; violência. 
http://dx.doi.org/10.5902/1984686X67913

\section{ABSTRACT}

The article aims to discuss the vulnerabilities and exclusions experienced by children and adolescents with disabilities, as well as to analyze the conditions of this population about situations of violence, especially within the family. Therefore, disability and violence, and their social connectors, are also the focus of this article. The study is based on a qualitative approach with a descriptive-analytical perspective, resorting mainly to documentary sources contained in public sites, educational censuses, and institutional reports from the municipal social assistance secretariats of the municipalities under study themselves as primary sources of research. The locus of analysis occurred in two municipalities in Parana, belonging to the metropolitan region of Curitiba/PR, between the years 2015 to 2021 . The data mapped situations of aggression and mistreatment and allowed a cross analysis of the categories: economic situation of families and gender. Among the results found, the following stand out: the relationship between the precarious socioeconomic conditions of families and disability; the extent to which children and adolescents with disabilities experience higher rates of violence compared to their non-disabled peers; as for the gender issue, municipality A revealed that $79.66 \%$ of the violence was against females, while municipality B showed that $75 \%$ of cases of violence were against males. The conclusions point to the need for intensifying studies on disability and violence in relation to other social connectors; the importance of expanding the support network for families and the qualified training of health and education professionals, as a public policy.

Keywords: Child and teenager; deficiency; violence.

\section{RESUMEN}

El artículo tiene como objetivo discutir las vulnerabilidades y exclusiones que viven los niños, niñas y adolescentes con discapacidad, así como analizar las condiciones de esta población frente a situaciones de violencia, especialmente en el ámbito familiar. Por lo tanto, la discapacidad y la violencia y sus conectores sociales son el tema central de este artículo. El estudio se basa en un enfoque cualitativo con una perspectiva descriptivo-analítica, recurriendo principalmente a fuentes documentales contenidas en sitios públicos, censos educativos e informes institucionales de las secretarías municipales de asistencia social de los municipios en estudio, ellos mismos como fuentes primarias de investigación. El locus de análisis ocurrió en dos municipios de Paraná, pertenecientes a la región metropolitana de Curitiba / PR, entre los años 2015 al 2021. Los datos mapearon situaciones de agresión y abuso y permitieron un análisis cruzado de las categorías: situación económica de las familias y género. Entre los resultados encontrados destacan: la relación entre las precarias condiciones socioeconómicas de las familias y la discapacidad; la medida en que los niños y adolescentes con discapacidad experimentan tasas más altas de violencia en comparación con sus compañeros sin discapacidad; en cuanto, al tema de género, el municipio A reveló que $79.66 \%$ de la violencia fue contra mujeres, mientras que el municipio B mostró que $75 \%$ de los casos de violencia fueron contra hombres. Las conclusiones apuntan a la necesidad de intensificar los estudios sobre discapacidad y violencia en relación con otros conectores sociales; la importancia de ampliar la red de apoyo a las familias y la formación calificada de los profesionales de la salud y la educación, como política pública.

Palabras clave: Niño y adolescente; deficiencia; violência. 
http://dx.doi.org/10.5902/1984686X67913

\section{Introdução}

Este estudo traz à tona o complexo quadro da violência contra crianças e jovens com deficiência e o adensamento de suas implicações, quando analisadas a partir do cenário de vulnerabilidades que envolvem para além da condição de ser criança ou jovem com deficiência. Partimos da perspectiva que determinantes sociais, como gênero e classe social, precisam ser analisados como possíveis potencializadores nos processos de opressão e de exclusão e podem gerar quadros diferenciados de violência, que vão desde o abandono, a negligência até a violência psicológica e/ ou física.

Por outro lado, a experiência das autoras deste estudo, há mais de doze anos com crianças e adolescentes que apresentam deficiência e sofrem violência, aponta que o reconhecimento dos sinais de maus-tratos pode ser dificultado pela incapacidade desses sujeitos em verbalizar que estão sendo maltratados, ou por não compreenderem, que estão sendo agredidos. Os fatores de risco à violência relacionados a uma criança ou adolescente com deficiência, pautam-se na sua alta dependência de cuidados e suportes vindos, muitas vezes, de seus próprios agressores, que na maior parte das situações pertencem ao seu próprio núcleo familiar. Neste sentido, a falta de serviços de apoio à família e o despreparo de profissionais da educação e da saúde, quer pela precariedade de conhecimento ou de compreensão sobre deficiência, são fatores que podem contribuir para que o quadro de violência contra esses sujeitos se intensifique e permaneça invisibilizado em nossa sociedade (GONZALVO, 2002; BARROS, 2014).

O conjunto de vulnerabilidades que envolve crianças e adolescentes com deficiência e suas famílias, tende a se intensificar quando essas apresentam um quadro de isolamento social e não estão inseridas em programas ou serviços de ajuda, destinados à redução da tensão emocional. Como destacado por Barros (2014), a restrição à vida social pode acontecer com famílias de crianças com deficiência, pois esses pais acreditam que, restringindo o convívio social da criança, evitarão uma possível rejeição a seu filho e, também, a sua família. Acreditamos que o isolamento social impede a interação da família e a construção de laços sociais, o que contribui para o processo histórico de exclusão.

A complexidade deste quadro tem sido destacada em muitos estudos que demonstram o quanto o risco à violência contra crianças e adolescentes com deficiência precisa ser compreendido no contexto dos fatores sociais, culturais e econômicos, somado à falta de políticas públicas de apoio às famílias e às pessoas com deficiência (PEDRO- 
http://dx.doi.org/10.5902/1984686X67913

VIEJO; GOMEZ-BENGOECHEA, 2006; CAVALCANTE; GOLDSON, 2009; CAVALCANTE; MINAYO, 2009).

Em que pese 0 arcabouço legislativo de proteção aos direitos das pessoas com deficiência e da criança e do adolescente no Brasil, com destaque para a Lei n. 8.069/1990, que institui o Estatuto da Criança e do Adolescente; o Decreto no 6.949/ 2009, que ratifica a Convenção da ONU sobre os Direitos das Pessoas com Deficiência (2006) e passa a configurar com status de Emenda Constitucional; a Lei oㅜ 13.146/ 2015, que institui a Lei Brasileira de Inclusão da Pessoa com Deficiência, conhecida como Estatuto da Pessoa com Deficiência, a efetivação de práticas educacionais e políticas públicas concretas de proteção a esses segmentos ainda está longe de ser legitimada em nosso país. Esta fragilidade e ineficiência ficou evidenciada por ocasião da pandemia da COVID 19, denunciada de modo recorrente pela mídia falada e escrita. Dentre as medidas importantes, mas ainda tímidas, está a Lei no 14.022, de 7 de julho de $2020^{1}$, que dispõe sobre medidas de enfrentamento à violência doméstica e familiar contra a mulher e de enfrentamento à violência contra crianças, adolescentes, pessoas idosas e pessoas com deficiência durante a pandemia.

Entendemos que o enfrentamento à violência contra crianças e adolescentes com deficiência passa pela eficácia de um ordenamento jurídico atento à concretização de políticas e práticas inclusivas. Os profissionais, por sua vez, precisam estar atentos aos sinais de violência, identificando-os e, conforme preconiza o Estatuto da Criança e Adolescente, notificando o Conselho Tutelar, ou outro órgão competente na ausência deste, para que as medidas de proteção cabíveis e demandadas ao Sistema de Garantia de Direitos das Crianças e Adolescentes sejam realizadas e para que possam, também, dar suporte às famílias (BARROS, 2014).

A compreensão sobre deficiência e vulnerabilidade à violência tem sido pauta de pesquisas de Diniz (2003, 2007); Mello (2009, 2014, 2015); Cavalcante (2009); Gesser (2012); Nuemberg (2012), entre outros, que têm se dedicado a investigar as vivências de opressão e exclusão social enfrentadas pelas pessoas com deficiência, enfocando a análise na relação entre a temática da deficiência e aspectos transversais como a pobreza, a violência e o gênero. Compactuamos com esses pressupostos e reconhecemos que a necessidade do cruzamento de conectores sociais é fundamental em estudos que primem pelos diretos das pessoas com deficiência e se tornam mais relevantes quando essas são crianças ou adolescentes. 
http://dx.doi.org/10.5902/1984686X67913

Posto isso, destacamos que este estudo objetivou discutir as vulnerabilidades e exclusões vivenciadas por crianças e adolescentes com deficiência, assim como analisou as condições dessa população no que se refere às situações de violência, sobretudo, a intrafamiliar.

\section{Conectores sociais como fatores de análise nos estudos sobre} vulnerabilidade à violência contra crianças e adolescentes com
deficência

Para Diniz (2007), a diversidade não ocorre somente por diferenças orgânicas causadas por algum tipo de deficiência, pois "assim como as mulheres são oprimidas por causa do gênero, as pessoas com deficiência são oprimidas por causa do corpo com lesões" (p. 59). Neste ensejo, a associação da deficiência com outros conectores sociais como raça, gênero e classe social, entre outros, pode potencializar processos de opressão, vulnerabilidade, desigualdade social e exclusão a esse coletivo. Com isso, os casos tornamse mais complicados quando as crianças e adolescentes pertencem a múltiplos círculos de grupos oprimidos.

Para analisar os conectores sociais que envolvem a violência contra crianças e adolescentes com deficiência, é preciso considerar o quanto a desigualdade e a exclusão social são geradoras de violência. No que se refere ao Brasil, ainda carecemos de políticas públicas permanentes e eficientes que combatam situações de violência, que encontram suas raízes na segregação social e educacional, na discriminação e nos preconceitos que são dirigidos às pessoas com deficiência. Obviamente, estado e família são fundamentais para garantir o desenvolvimento com qualidade de uma criança ou de um adolescente com deficiência, que necessitará de suportes e acolhimento para sua inclusão social e educacional.

Diversas ações voltadas às famílias são fundamentais para combater a violência contra crianças com deficiência, dentre elas, o apoio a pais e responsáveis para conhecer e entender os direitos de seus filhos, além de programas que auxiliem a família a ter uma rede de apoio que envolva outras pessoas da própria comunidade (BARROS,2014; GONZALVO, 2002). Tais medidas são cruciais para evitar sobrecarregar os pais, já que esse é um dos pontos identificados como uma das principais causas de violência intrafamiliar (MINAYO, 2009). Desta feita, fatores de proteção e a existência de programas 
http://dx.doi.org/10.5902/1984686X67913

de intervenção precoce, por meio de serviços de pré e pós-natal, visitas domiciliares e programas para o desenvolvimento de qualidade na primeira infância são essenciais (BARROS, 2014).

O trabalho cotidiano com essas famílias tem demonstrado que essa rede de apoio à prevenção da violência intrafamiliar deve abarcar tanto a família extensa (avós, tios, padrinhos etc.), quanto de vínculos positivos na comunidade, que possam ajudar e dar suporte nas tarefas diárias dos pais ou parentes que exerçam a função de cuidado de crianças e adolescentes com deficiência (GONZALVO, 2002).

Posto isso, evidenciamos a importância de trazer à tona a relação entre conectores sociais nos estudos sobre violência contra crianças e adolescentes com deficiência. Todavia, dada a necessária delimitação que requer a construção de um artigo e as especificidades da temática em tela, elegemos os seguintes conectores sociais para análise: vulnerabilidade econômica familiar e gênero presentes nos dados coletados dos dois municípios lócus deste estudo, ambos localizados na região metropolitana de Curitiba, os quais caracterizamos como Municípios A e B.

Destacamos, também, que a presente pesquisa se apoiou na abordagem qualitativa, a partir da perspectiva descritivo-analítica. Para tanto, recorreu às fontes documentais que apontavam dados sobre a violência vivenciada por crianças e adolescentes com deficiência nos dois municípios paranaenses estudados, entre os anos de 2015 e 2021 . No que se refere às fontes documentais analisadas, apontamos que informações constantes em sítios públicos, censos educacionais e relatórios institucionais das secretarias municipais de assistência social dos municípios em estudo, relatórios esses que se caracterizam, nesta pesquisa, como fontes primárias. Portanto, o cruzamento dos conectores sociais, gênero e situação econômica, instituíram-se os eixos temáticos fundamentais para analisar facetas da identidade social de crianças e/ou adolescentes com deficência e de suas famílias.

O município ao qual caracterizamos como "A" para esta pesquisa é de porte médio, e o segundo mais populoso da mesorregião de Curitiba. De acordo com os dados do IBGE (2010), apresentava população superior a 263 mil habitantes, por sua vez, a estimativa para 2021 é de 334.620 habitantes. O município A é a quinta maior área da Região Metropolitana de Curitiba. Já o Município descrito na pesquisa como "B" possuía, segundo o IBGE (2010),

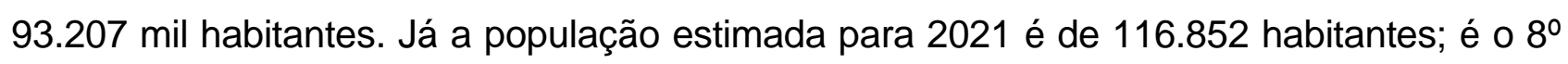
município mais populoso da região metropolitana e 0 6ºm termos de densidade média 
http://dx.doi.org/10.5902/1984686X67913

populacional com $49 \%$ dos habitantes residindo na área urbana e 51\% na área rural (IBGE, 2010).

No intuito de objetivar uma maior aproximação de informações sobre o objeto deste estudo, uma vez que não existe censo demográfico específico que aponte o quantitativo de crianças e adolescentes com deficiência, de 0 a 17 anos, utilizamos os dados do Censo Escolar como referência para estabelecer a relação entre o quantitativo dessa população nos dois municípios em estudo.

Tabela 1 - Censo Escolar dos Municípios A e B - Anos de 2015 a 2019

\begin{tabular}{l|c|c|c|c|c}
\hline \multicolumn{1}{c|}{ CENSO EDUCAÇÃO BÁSICA } & $\mathbf{2 0 1 5}$ & $\mathbf{2 0 1 6}$ & $\mathbf{2 0 1 7}$ & $\mathbf{2 0 1 8}$ & $\mathbf{2 0 1 9}$ \\
\hline Censo Escolar de 0-17 anos Município A & 64.918 & 65.873 & 66.444 & 67.131 & 67.247 \\
\hline Censo Escolar de 0-17 anos Município B & 21.581 & 21.694 & 21.283 & 21.760 & 21.556 \\
\hline \multicolumn{1}{c}{ CENSO EDUCAÇÃO ESPECIAL } & $\mathbf{2 0 1 5}$ & $\mathbf{2 0 1 6}$ & $\mathbf{2 0 1 7}$ & $\mathbf{2 0 1 8}$ & $\mathbf{2 0 1 9}$ \\
\hline $\begin{array}{l}\text { Censo Educação Especial 0-17 anos } \\
\text { Município A }\end{array}$ & 1168 & 1224 & 1426 & 1793 & 2078 \\
\hline $\begin{array}{l}\text { Censo Educação Especial 0-17 anos } \\
\text { Município B }\end{array}$ & 514 & 551 & 601 & 627 & 612 \\
\hline
\end{tabular}

Fonte: Reorganizada pelas autoras com base nos microdados do INEP (2021).

Os dados da tabela 1 indicam que, no período entre 2015 e 2019, o município A apresentou 66.323 matrículas de estudantes, na idade entre 0 e 17 anos, na Educação Básica, e, dentre essas matrículas, apenas 2,4\%, ou seja, 1.616 indivíduos destinaram-se aos estudantes público-alvo da educação especial. Já o Município B apresentou 21.580 matrículas na educação básica de 0 a 17 anos. Deste montante, 581 matrículas fazem parte do público-alvo da educação especial, o que representa 2,7\%. Os dados do ano de 2020 não foram apresentados, pois não estavam disponíveis no site do INEP até a conclusão deste estudo.

Posto este mapeamento, que revelou uma estimativa da população com deficiência matriculada por meio do Censo Escolar, buscamos dados acerca das famílias inseridas no Cadastro Único, visto que é um instrumento que reúne informações sobre as famílias em situação de vulnerabilidade econômica e pobreza para fins de inclusão em programas da política da assistência social e redistribuição de renda. Para isso, utilizamos como fontes os dados disponibilizados para domínio público, pelo Ministério da Cidadania, através do sistema do CECAD. O terceiro documento utilizado para análise se deu por meio dos relatórios ${ }^{2}$ institucionais das Secretarias Municipais de Assistência Social dos municípios em estudo. O cruzamento desses dados teve como foco obter as informações 
http://dx.doi.org/10.5902/1984686X67913

socioeconômicas das famílias referenciadas no Cadastro Único, especificadamente, daquelas que possuem em seu núcleo familiar filho (s) com deficiência.

Tabela 2 - Registros do Cadastro Único que apontam crianças e adolescentes com e sem deficiência no ano de 2021

\begin{tabular}{l|c|c}
\hline \multicolumn{1}{c|}{ Município A } & Sim & Não \\
\hline 0 - 4 Anos & 187 & 7.349 \\
\hline 5 - 6 Anos & 133 & 3.773 \\
\hline 7 - 15 Anos & 710 & 11.934 \\
\hline 16-17 Anos & 154 & 3.375 \\
\hline TOTAL & 1.184 & 26.431 \\
\hline \multicolumn{1}{c|}{ Município B } & Sim & Não \\
\hline 0 - 4 Anos & 80 & 3.744 \\
\hline $5-6$ Anos & 53 & 1.883 \\
\hline 7 - 15 Anos & 257 & 5.613 \\
\hline 16-17 Anos & 43 & 1.459 \\
\hline TOTAL & 433 & 12.699 \\
\hline
\end{tabular}

Fonte: Organizada pelas autoras com base nos microdados do Cecad - Ministério da Cidadania (2021).

Os resultados encontrados demonstraram que, no município $A$, dentre a média obtida de 1.616 pessoas com deficiência, considerando os dados do Censo Escolar para a faixa etária de zero (0) à dezessete (17) anos, cerca de 73,3\% receberam benefícios do Programa Bolsa Família. Já no Município B, verificamos que $74,5 \%$, das famílias foram beneficiadas pelo Programa Bolsa Família. Estes dados indicam a vulnerabilidade econômica das famílias que possuem filho (s) com deficiência, pois este valor pode tanto ser complementar, como a única renda existente da família.

Criado em 2003, o Programa Bolsa Família ${ }^{3}$ propõe a unificação dos Programas de Transferência de Renda no Brasil e traz, na área da educação, a condicionalidade de que as famílias para receberem o benefício mensal, devem matricular seus filhos de 6 a 15 anos na escola, com frequência mínima de $85 \%$ das aulas, e aquelas que possuem em seu núcleo familiar jovens de 16 a 17 anos devem matriculá-los na escola, com frequência mínima de 75\% das aulas. Estudos de Cacciamali, Tatei, Batista (2010); Silva, Brandão, Dalt (2012); Fahel et al (2012); Campello \& Neri, (2014); Santos et al (2019) dentre outros, apontam os impactos da Bolsa Família nas matrículas e inclusão social. Embora, cientes de que as políticas públicas decorram de pressões sociais e que sustentam, também, interesses contraditórios, as condicionalidades postas aos núcleos familiares com relação à matrícula e permanência escolar de seus filhos é um instrumento que insere crianças e 
http://dx.doi.org/10.5902/1984686X67913

jovens que, historicamente, foram excluídos da escola, como é o caso daquelas que apresentam deficiência.

Para Cavalcante et al (2009), mapeamentos que relacionam deficiência e pobreza são escassos e os que existem indicam que, embora nem todas as pessoas com deficiências façam parte daquelas que apresentam vulnerabilidades econômicas, o grupo de pessoas com deficiência está entre os com maiores riscos de viver em situação de pobreza, especialmente nos países em desenvolvimento e com exclusão social de determinados grupos. Os estudos de McDonald, Keys, Balcazar (2007), corroboram com as conclusões de Cavalcante et al (2009), apontando que a falta de recursos financeiros exacerba múltiplas privações que desencadeiam para deficiências e desigualdades mais severas, gerando um ciclo de deficiência, pobreza e exclusão.

Diante das inúmeras variáveis que os estudos sobre deficiência e pobreza nos indicam, destacamos, a seguir, um panorama dos municípios em estudo, quanto às questões de renda, conforme os dados gerados pelo Cadastro Único.

Para análise da situação socioeconômica das famílias dos municípios em estudo, utilizamos o critério de renda per capita apontado pelo Ministério da Cidadania para classificação de vulnerabilidade de renda, distribuídas a partir dos seguintes critérios: situação de extrema pobreza (com renda mensal por pessoa de até $R \$ 89,00$ ); situação de pobreza (com renda mensal por pessoa entre $R \$ 89,01$ até $R \$ 178,00$ por pessoa) e baixa renda, que são as famílias que possuem rendimentos de até meio salário mínimo por pessoa ( $R \$ 550$, em 2021) ou que ganham até três salários mínimos de renda mensal total ( $R$ \$ 3.300).

Tabela 3 - Situação Socioeconômica das famílias que possuem um membro com deficiência nos Município A e B - Ano 2021

\begin{tabular}{l|c|c|c}
\hline \multicolumn{1}{|c|}{ MUNICÍPIO A } & SIM & NÃO & $\%$ \\
\hline Extrema Pobreza & 1.418 & 9.677 & 13 \\
\hline Pobreza & 418 & 3.802 & 10 \\
\hline Baixa Renda & 2.446 & 10.668 & 19 \\
\hline Acima de 1/2 S.M. & 2.826 & 8.527 & 25 \\
\hline \multicolumn{1}{c|}{ MUNICÍPIO B } & SIM & NÂO & $\%$ \\
\hline Extrema Pobreza & 863 & 7.157 & 11 \\
\hline Pobreza & 163 & 1.542 & 10 \\
\hline Baixa Renda & 906 & 3.302 & 22 \\
\hline Acima de 1/2 S.M. & 929 & 1.999 & 32 \\
\hline
\end{tabular}

Fonte: Dados sistematizados pelas autoras a partir de informações obtidas do Cecad - Ministério da Cidadania (2021). 
http://dx.doi.org/10.5902/1984686X67913

No Município A, constatamos que dentre as famílias em situação de extrema pobreza, 13\% possuem um membro com deficiência; já em situação de pobreza, 10\% das famílias possuem um filho com deficiência; por sua vez, aquelas que estão no patamar de baixa renda representam $19 \%$ desta condição. É de $25 \%$ o percentual de famílias que apresentam um filho com deficiência, com renda per capita acima de $1 / 2$ salário. Por sua vez, no Município $B$, o percentual de famílias com pelo menos um membro com deficiência em situação de extrema pobreza foi de $11 \%$; em situação de pobreza, foi de $10 \%$ e baixa renda representou $22 \%$. Sendo que, é de $32 \%$ o percentual das famílias que possuem um membro da família com renda per capita acima de $1 / 2$ salário. Os dados demonstram o quanto 0 percentual total de famílias, nos dois municípios, que apresentam vulnerabilidade social e que possuem um filho entre 6 e 17 anos é alto, indicando o quanto se faz necessário potencializar políticas públicas destinadas à inclusão social e educacional dessas crianças e jovens. Lembramos que, neste percentual, não estão inseridos os dados das crianças de 0 a 5 anos com deficiência, que estão excluídos juntamente com suas famílias dessa política pública de inserção social e educacional.

Compreender o impacto desse cenário, na precária renda familiar ou na falta dela, e o que representa para os cuidadores diretos possuir um filho com deficiência, se faz necessário. A experiência, enquanto profissionais de educação com famílias em situação de vulnerabilidade social, nos aponta que, muitas vezes, a chegada de um bebê ou o recebimento de um diagnóstico de deficiência de um filho acarreta, principalmente para a mãe, a saída do mercado de trabalho ou a busca de fontes informais de renda. Barros (2014) aponta que a falta de garantia acerca das necessidades básicas supridas, somada à falta de recursos fundamentais, pode representar, para muitas famílias, um forte quadro de estresse, que as tornam mais suscetíveis, inclusive à violência intrafamiliar.

Da mesma forma que a pobreza gera vulnerabilidades, também impõe uma condição limitante que impossibilita às famílias de utilizar e acessar os recursos e serviços públicos, dado à falta de condições que the são impostas, pela desigualdade social, de conhecer seus direitos. Portanto, discutir a relação entre "pobreza e deficiência" e, consequentemente, a temática da violência, precisa ser uma ação prioritária da agenda pública, em que devem estar inclusas as estratégias de redução da pobreza associadas aos programas de prevenção de incapacidades e maus tratos (CAVALCANTE; GOLDSON, 2009). 
A seguir, apresentamos dados sobre a violência contra crianças e adolescentes com deficiência nos municípios em estudo a partir dos atendimentos ocorridos nas Unidades do Centro de Referência Especializado de Assistência Social (CREAS), que é uma unidade pública da Assistência Social que atende pessoas que vivenciam situações de violações de direitos ou de violências de assédio, de discriminação, de abuso, de violência ou por demandar cuidados em razão da idade ou deficiência (BRASIL, 2011).

Tabela 4 - Violações de Direitos Atendidos na Unidade do CREAS nos Município A e B por Ano (2015 -2019)

\begin{tabular}{l|c|c|c|c|c}
\hline \multicolumn{1}{c|}{ MUNICÍPIO A } & $\mathbf{2 0 1 5}$ & $\mathbf{2 0 1 6}$ & $\mathbf{2 0 1 7}$ & $\mathbf{2 0 1 8}$ & $\mathbf{2 0 1 9}$ \\
\hline Criança & 8 & 6 & 2 & 3 & 5 \\
\hline Adolescente & 7 & 16 & 5 & 4 & 3 \\
\hline \multicolumn{1}{c|}{ MUNICÍPIO B } & $\mathbf{2 0 1 5}$ & $\mathbf{2 0 1 6}$ & $\mathbf{2 0 1 7}$ & $\mathbf{2 0 1 8}$ & $\mathbf{2 0 1 9}$ \\
\hline Criança & - & - & - & 2 & 1 \\
\hline Adolescente & - & - & 1 & - & - \\
\hline
\end{tabular}

Fonte: Organizado pelas autoras a partir dos relatórios disponibilizados pelas Secretarias de Assistência Social dos Municípios em estudo (2021).

Durante os cinco anos analisados para esta pesquisa, observamos que no Município "A" houve 59 casos de crianças e adolescentes com deficiência que sofreram violência do tipo física, sexual, psicológica ou negligência; no Município "B" foram constatados 4 casos. Mesmo considerando que a diferença da média de crianças e adolescentes com deficiência a partir dos dados do Censo escolar é 3 vezes maior no Município "A", em comparação ao Município "B", estes dados ainda não explicam essa diferença.

A invisibilidade das denúncias de violência contra crianças e adolescentes com e sem deficiência precisa ser considerada, uma vez que diversos estudos vêm demonstrando a dificuldade destas informações chegarem até aos órgãos competentes e da subnotificação de tais casos, o que pode gerar grande diferença de um município para outro. Outra questão a ser posta, refere-se ao registro das informações, uma vez que a especificidade da deficiência não é priorizada na hora dos atendimentos, conforme os estudos realizados a partir dos relatórios institucionais das secretarias municipais de assistência social dos municípios em estudo. Estas discussões são primordiais para a proposição de políticas públicas de prevenção à violência contra criança e adolescentes com deficiência, uma vez que esta apresenta contornos específicos e ainda mais difíceis de serem identificados e combatidos.

Os dados obtidos dos referidos relatórios institucionais com relação às crianças e adolescentes com ou sem deficiência, que sofreram violência, estão dimensionados nas figuras 1 e 2 a seguir: 
Figura 1 - Distribuição de crianças e adolescentes que sofreram violência com e sem deficiência inscritas no Cadastro Único no Município A - ano de 2015 -2019

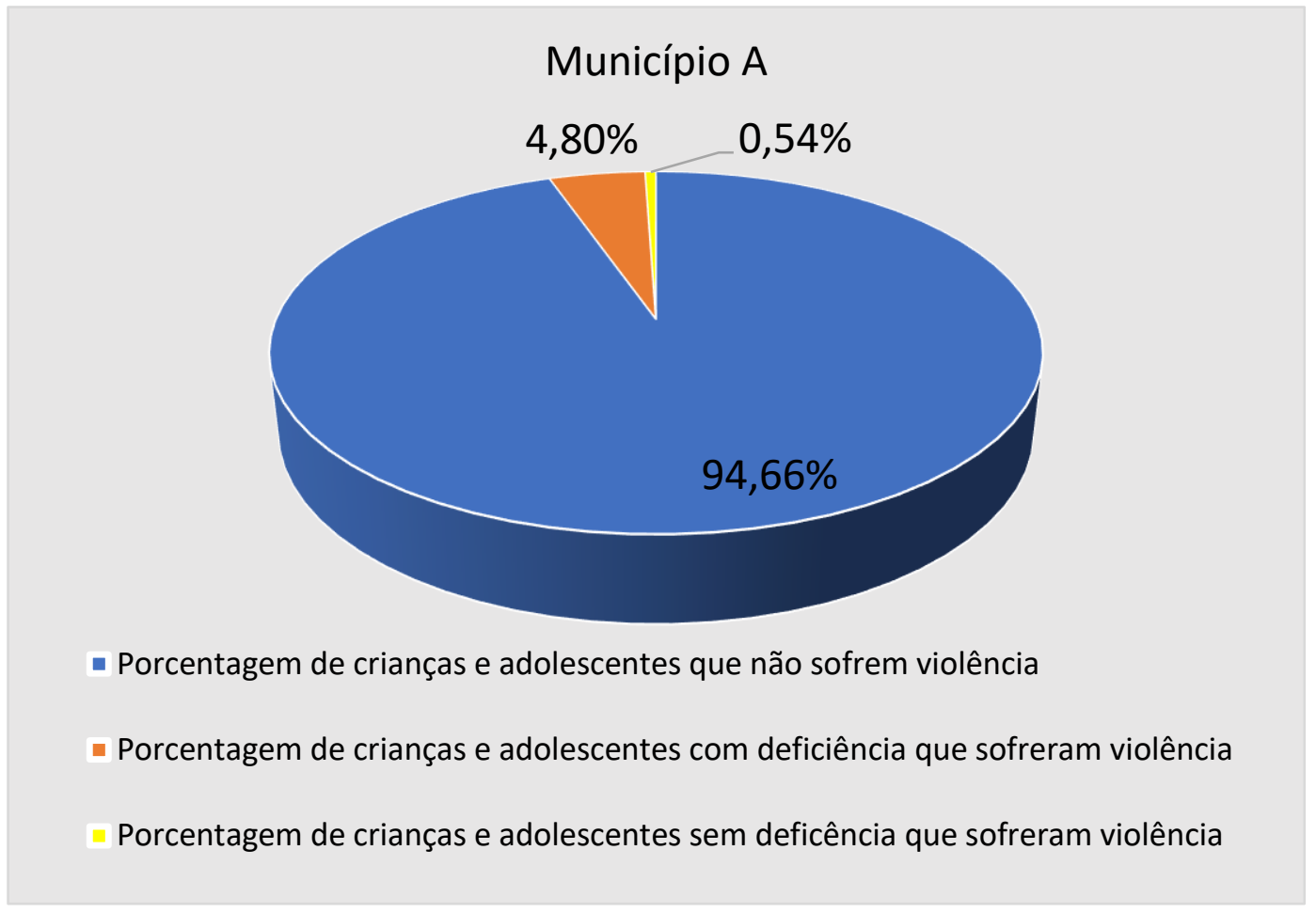

Fonte: Organizado pelas autoras a partir dos relatórios disponibilizados pelas secretarias de assistência social dos municípios em estudo (2021).

Figura 2 - Distribuição de crianças e adolescentes que sofreram violência com e sem deficiência inscritas no Cadastro Único no Município A - ano de 2015 -2019

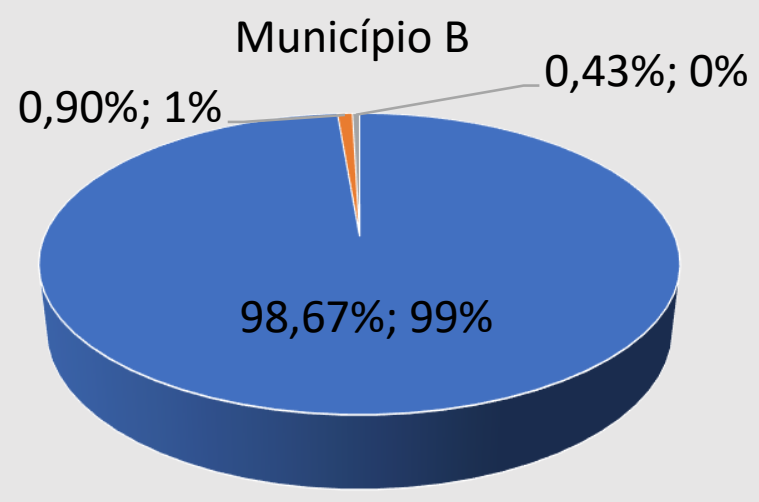

- Porcentagem de crianças e adolescentes inscritos que não sofrem violência

- Porcentagem de Crianças e adolescentes com deficiência que sofreram violência

- Porcentagem de crianças e adolescentes sem deficência que sofreram violência

Fonte: Organizado pelas autoras a partir dos relatórios disponibilizados pelas secretarias de assistência social dos municípios em estudo (2021).

Revista Educação Especial | v. 34 | 2021 - Santa Maria

Disponível em: https://periodicos.ufsm.br/educacaoespecial 
Podemos observar nos gráficos apresentados que, no Município A, 4,8\% das crianças e adolescentes com deficiência sofreram algum tipo de violência, entre os sujeitos da mesma faixa etária sem deficiência este percentual ficou em $0,54 \%$. No Município B, o percentual dentre aqueles com deficiência que sofreram violência foi de $0,9 \%$, já os seus pares sem deficiência apresentaram percentual de 0,43\%. Estes resultados demonstram que, nos dois municípios analisados, crianças e adolescentes com deficiência experimentam taxas mais altas de violência em comparação com pares sem deficiência. Este dado corrobora com outras pesquisas da área sobre o assunto (BARROS, 2014;BARROS; DESLANDES, 2016; ALGOOD et al. 2011).

Crianças e adolescentes com deficiência são expostas a formas específicas de violência, que são diferentes daquelas experimentadas por seus pares sem deficiência. Entre elas podemos citar a restrição, o abuso sexual durante as rotinas diárias de higiene, remoção ou controle de meios de comunicação, violência no decorrer de tratamento, medicação excessiva ou suspensão de medicação (BRASIL, 2002), além de estarem sujeitas a uma violência que é motivada pelo preconceito contra deficiência, pelo estigma e discriminação.

As crianças com deficiência enfrentam várias formas de violência que se apresentam em diversas configurações. As dificuldades na identificação de violência intrafamiliar estão relacionadas, entre outros fatores, ao fato de que profissionais, muitas vezes, não têm as habilidades para reconhecer cedo os sinais de risco de violência, nem o conhecimento sobre como abordar as famílias e oferecer apoio (GONZALVO, 2002; BARROS, 2014).

Ainda apontamos para a necessidade de que programas e serviços voltados à defesa deste público mantenham canais de denúncia, para que crianças e adolescentes vítimas de violência possam pedir ajuda quando necessário. Tais programas e atividades de prevenção à violência destinados a este público devem ser acessíveis às crianças e adolescentes com deficiência de modo a se adequar às suas condições biopsicossociais e suas características culturais e de gênero.

\section{Crianças e adolescentes com deficiência no contexto da violência de gênero}

Existe uma naturalização e certa tolerância dentro da sociedade para com a violência de gênero, pois como ela ocorre dentro dos lares, torna o ato sujeito à privacidade. Isso faz com que a violência se torne invisível ou difícil de ser detectada e, na maioria dos casos, 
não denunciada e julgada. $O$ fato de ser uma violência cometida dentro do âmbito da família nos leva a outras duas questões: o cuidado e a dificuldade da denúncia. Os agressores mais comuns neste tipo de ocorrência são familiares e prestadores de cuidados. Meninas e mulheres também podem ser expostas, entretanto, há outros autores potenciais que incluem parentes do sexo masculino, entre eles o pai, o padrasto e os irmãos (CAVALCANTE; BASTOS, 2009).

Nesta direção, visando à proteção de crianças e adolescentes que possuem deficiência, destacamos da Convenção dos Direitos das Pessoas com Deficiência dois artigos: o primeiro destinado aos direitos das mulheres com deficiência e o segundo aos das crianças.

Art. 6: Os Estados Parte reconhecem que as mulheres e meninas com deficiência estão sujeitas a múltiplas formas de discriminação e, portanto, tomarão medidas para assegurar às mulheres e meninas com deficiência o pleno e igual exercício de todos os direitos humanos e liberdades fundamentais (BRASIL, 2009, não p.).

Art. 7: 1. Os Estados Partes tomarão todas as medidas necessárias para assegurar às crianças com deficiência o pleno exercício de todos os direitos humanos e liberdades fundamentais, em igualdade de oportunidades com as demais crianças (BRASIL, 2009, não p.).

O documento traz um avanço no sentido de reconhecer as vulnerabilidades sobrepostas vivenciadas por meninas e mulheres com deficiência e dá visibilidade ao problema, trazendo luz às situações de discriminação e violência vividas diariamente por esse grupo (LOPES, 2009). Quando a deficiência se agrega à condição de gênero, infância e adolescência, além do acréscimo de mais um fator de discriminação, a vulnerabilidade às situações de exclusão, segregação e violência se potencializam (DINIZ, 2007).

Dentre os conectores sociais que se inter-relacionam com a deficiência, a infância e a adolescência, apontamos para a necessidade de analisar a violência a partir da categoria gênero. Conforme já mencionado, os dados referentes ao gênero foram analisados a partir dos relatórios disponibilizados pelas secretarias de assistência Social dos munícipios A e B durante os anos de 2015 a 2019, conforme retratam as Figuras 3 e 4, a seguir: 
http://dx.doi.org/10.5902/1984686X67913

Figura 3 - Distribuição Média da Agressão Infligida a Crianças e Adolescentes com Deficiência por Gênero no Município A

\section{Município A -}

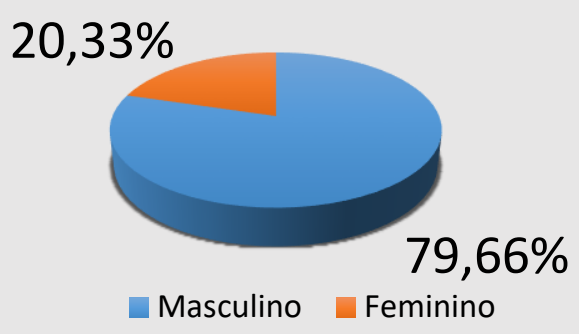

Fonte: Organizado pelas autoras a partir dos relatórios disponibilizados pelas secretarias de assistência social dos municípios em estudo (2021).

Figura 4 - Distribuição Média da Agressão Infligida a Crianças e Adolescentes com Deficiência por Gênero

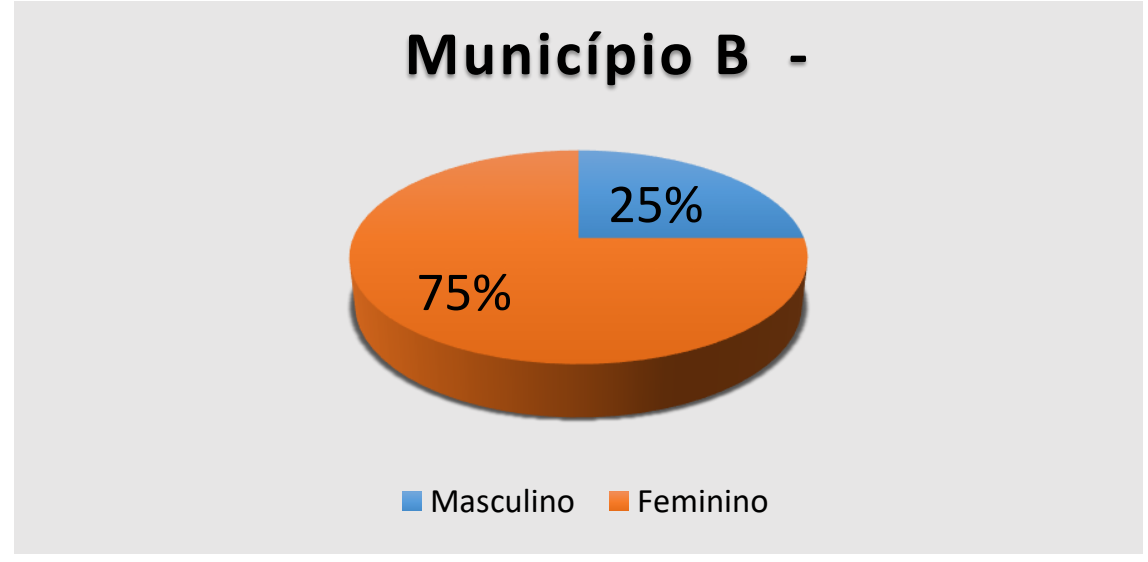

Fonte: Organizado pelas autoras a partir dos relatórios disponibilizados pelas secretarias de assistência social dos municípios em estudo (2021).

O município A revelou que $79,66 \%$ das violências declaradas contra crianças e adolescentes com deficiência, se deram para o gênero feminino, enquanto $20,3 \%$ foram relacionadas ao gênero masculino. Por sua vez, no município B observamos que $75 \%$ dos casos de violência foram contra o gênero masculino, e $25 \%$ das violências declaradas foram contra o gênero feminino. Novamente, observamos dados bem diferenciados entre os municípios, o que nos indica a necessidade de aprofundar como se efetivam os programas de apoio às famílias com crianças e jovens com deficiência nas duas realidades estudadas, sobretudo, àqueles destinados ao enfrentamento da violência, realizados pelo Centro de Referência Especializado de Assistência Social (CREAS). O fato de termos tanto o gênero 
http://dx.doi.org/10.5902/1984686X67913

feminino quanto o masculino sofrendo altos percentuais de violências, indica-nos a urgência do estabelecimento de políticas públicas eficientes para a criança e ao adolescente com deficiência.

As políticas públicas precisam considerar, também, a diversidade destes meninos e meninas com base na sua idade, orientação sexual, identidade de gênero, origem racial e étnica, diferentes deficiências e crenças (INWWD, 2011), e incorporá-las como beneficiárias das operações que investem diretamente na igualdade de gênero.

Diante deste cenário, as políticas públicas devem ser efetivas, pois, as situações de violência encontram suas raízes na discriminação e nos preconceitos dirigidos às pessoas com deficiência, independente do gênero.

\section{Conclusões}

O presente estudo, ao apontar para a situação de violência sofrida por crianças e adolescentes com deficiência, demonstrou o quanto esses sujeitos e suas famílias, nos municípios em estudo, estão expostos a um quadro de vulnerabilidades, que sem dúvida fragilizam seus direitos humanos. A desigualdade e a exclusão social foram marcadamente evidenciadas ao analisarmos os dados referentes às famílias registradas no Cadastro Único. O mapeamento sobre a deficiência, no contexto do gênero, nos municípios estudados, apontou o quanto é necessário estabelecer políticas públicas eficientes para a criança e adolescente com deficiência, independente do gênero, em que pese às vulnerabilidades e violências sofridas, de modo contundente, contra as meninas e mulheres com deficiência.

Os resultados iniciais postos, neste artigo, demonstram o quanto pesquisas sobre crianças e adolescentes com deficiência em situação de violência necessitam realizar cruzamentos entre diversos conectores sociais. Da mesma maneira, apontamos a interseccionalidade como um caminho nos estudos destinados ao público-alvo da educação especial, capaz de desvelar a opressão, a dominação, a discriminação, a violência e a exclusão em nossa sociedade.

A escola, por meio de sua função social, é também o lócus que deve estar atenta aos seus estudantes - crianças e adolescentes - contra qualquer violação de seus direitos, quando esses possuem deficiência. O olhar precisa, além de conhecimento qualificado, sensibilidade e acolhimento, para atender às especificidades da própria deficiência. 
http://dx.doi.org/10.5902/1984686X67913

Por fim, é necessário que se concretizem políticas públicas de enfrentamento ao cenário apresentado, que o Estado e os agentes da rede de proteção, dentre os quais destacamos a escola e os profissionais envolvidos, aja desde a detecção precoce de sinais de maus tratos, até as intervenções que se fizerem necessárias, ocupando seu papel social de combate à violência contra crianças e adolescentes com deficiência.

\section{Referências}

ALGOOD, Carl Lee et al. Maltreatment of children with developmental disabilities: An ecological systems analysis. Children And Youth Services Review, n.33 p.1142-1148, 2011.

BARROS, Ana Cláudia Mamede Wiering de. Proteção e vulnerabilidade à violência familiar em crianças e adolescentes com deficiências. Tese de Doutorado em Saúde da Criança e da Mulher. Instituição de Ensino: Fundação Oswaldo Cruz, Rio de Janeiro Biblioteca Depositária: Biblioteca da Saúde da Mulher e da Criança, 2014.

BARROS, Ana Cláudia Mamede Wiering de; DESLANDES, Suely Ferreira; BASTOS, Olga Maria. A violência familiar, a criança e o adolescente com deficiências. Cad. Saúde Pública. n.6, v.32, p. e 00090415, 2016.

BRASIL. Ministério da Saúde. Violência intrafamiliar: orientações para prática em serviço / Secretaria de Políticas de Saúde. Brasília: Ministério da Saúde, 2001.

BRASIL. Decreto n. 6.949, de 25 de agosto de 2009. Promulga a Convenção Internacional sobre os Direitos das Pessoas com Deficiência e seu Protocolo Facultativo, assinados em Nova York, em 30 de março de 2007. Diário Oficial da União, 2009.

BRASIL. Estatuto da Criança e Adolescente. Lei 8.069, de 13 de julho de 1990. Brasília, 1990.

BRASIL. Lei 13.146, de 6 de julho de 2015. Institui a Lei Brasileira de Inclusão das

Pessoas com Deficiência (Estatuto da Pessoa com Deficiência). Diário Oficial da União, Brasília, 7 de julho 2015.

CACCIAMALI, Maria Cristina; TATEI, Fabio; BATISTA, Natália Ferreira. Impactos do Programa Bolsa Família federal sobre o trabalho infantil e a frequência escolar. Rio de Janeiro. Rev. econ. Contemp. n 2, v.14. p. 269-301, mai/ago, 2010.

CAMPELLO, Tereza; NERI Marcelo Côrtes (org.). Programa Bolsa Família: uma década de inclusão e cidadania: Sumário executivo. Brasília: Ipea, 2014.

CAVALCANTE, Fátima Gonçalves, BASTOS Olga Maria. Pessoas portadoras de deficiência e com necessidades especiais e situações de violência. In: Kathie Njaine Simone Gonçalves de Assis Patricia Constantino (Orgs.). Impactos da violência na saúde. Rio de Janeiro: Fiocruz, p.267 -297, 2009. 
CAVALCANTE, Fátima Gonçalves; GOLDSON, Edward. Análise da situação da pobreza e da violência entre crianças e jovens com deficiência nas Américas uma proposta de agenda debate. Ciência \& Saúde Coletiva. Rio de Janeiro, v. 14, n. 1, p. 7-20, 2009.

CAVALCANTE, Fátima Gonçalves; MINAYO, Maria Cecília de Souza. Representações sociais sobre direitos e violência na área da deficiência. Ciência \& Saúde coletiva. v. 14, n. 1, p. 57-66, fev., 2009.

CAVALCANTE, Fátima Gonçalves et al. Diagnóstico situacional da violência contra crianças e adolescentes com deficiência em três instituições do Rio de Janeiro. Ciência \& Saúde Coletiva. v.14, n.1, p.45-56, 2009.

DINIZ, Débora. Modelo Social da Deficiência: A Crítica Feminista. Série Anis 28, Brasília, Letras Livres, v.28, 2003.

DINIZ, Débora. O que é deficiência. São Paulo: Ed Brasiliense. Coleção Primeiros Passos, 2007.

FAHEL, Murilo et al. O impacto do Bolsa Família na inclusão educacional: análise da matrícula escolar em Minas Gerais. SER Social, Brasília, v. 14, n. 30, p. 98-126, jan./jun., 2012.

GESSER, Marivete; NUEMBERG, Adriano Henrique e TONELI, Maria Juracy Filgueiras. A Contribuição do Modelo Social da Deficiência à Psicologia Social. Psicologia \& Sociedade; v.24, n.3, p. 557-566, 2012.

GONZALVO, Gonçalo Olívan. Maltrato en niños con discapacidades: características y factores de riesgo. Anales Españoles de Pediatria. Espanha, v.56, n.3, p.219-223, 2002.

IBGE. Instituto Brasileiro de Geografia e Estatística. Censo Demográfico 2010: famílias e domicílios: resultados da amostra. Rio de Janeiro: IBGE; 2010. Disponível em: https://www.ibge.gov.br/estatisticas/sociais/populacao/9662-censo-demografico.Acesso em: 05 de maio de 2020.

INWWD. International Network of Women with Disabilities (INWWD). Violência contra Mulheres com Deficiência, 2019.

LOPES, Laís Vanessa Carvalho de Figueiredo. Convenção sobre os Direitos das Pessoas com deficiência da ONU, seu protocolo facultativo e a acessibilidade. 228 . Dissertação (Mestrado) Programa de Pós-Graduação em Direito da Pontifícia Universidade Católica de São Paulo. São Paulo, 2009

MCDONALD, Katherine E; KEYS, Christopher B; BALTAZAR Fabricio. Disability, race/ethnicity and gender: Themes of cultural oppression, acts of individual resistence. Am J Community Psychol, 2007.

MELLO, Anahí Guedes de. Gênero, deficiência, cuidado e capacitismo: uma análise antropológica de experiências, narrativas e observações sobre violências contra mulheres com deficiência. Dissertação. (Mestrado em Antropologia Social). Universidade Federal de Santa Catarina. Florianópolis, 2014. 
http://dx.doi.org/10.5902/1984686X67913

MELLO, Anahí Guedes de. Por uma abordagem Antropológica da Deficiência:

Pessoa, Corpo e Subjetividade. 86f Trabalho de Conclusão de Curso apresentado ao curso de graduação em Ciências Sociais da Universidade Federal de Santa Catarina, Florianópolis, p.264, 2009.

MELO, Carlos Vinicius Gomes. Estratégias de enfrentamento de pessoas negras e com deficiência frente ao duplo estigma. 186f. Dissertação (Mestrado). Universidade Federal da Bahia. Instituto de Psicologia. Salvador, 2014.

MINAYO, Maria Cecília de Souza. Conceitos, teorias e tipologias de violência: a violência faz mal à saúde. In: Kathie Njaine Simone Gonçalves de Assis Patrícia Constantino (Orgs.). Impactos da violência na saúde. Rio de Janeiro: Fiocruz.p.21-43, 2009.

OZEMELA, Luana Marques Garcia; ORTIZ, Diana e URBAN, Anne-Marie .Violence against Women and Girls with Disabilities. Inter-American Development Bank. 2019.

PASSOS, Regina Lucia Da violência sexual e outras ofensas contra a mulher com deficiência Dissertação (mestrado) $107 f$ - Fundação Oswaldo Cruz, Escola Rio de Janeiro, 2019.

PEDRO-VIEJO, Ana Berástegui; GOMEZ-BENGOECHEA, Blanca. Los menores con discapacidad como víctimas de maltrato infantil: una revisión. Intervención Psicosocial, Madrid, v.15, n.3, p.296-306, 2006.

SANTOS, Mariana Cristina Silva et al. Programa Bolsa Família e indicadores educacionais em crianças, adolescentes e escolas no Brasil: revisão sistemática. Ciência \& Saúde Coletiva, v.24, n.6, p.2233-2247, 2019.

Silva, Anderson Paulino, Brandão André, Dalt, Salete da. Educação e pobreza: o impacto das condicionalidades do Programa Bolsa Família. Revista Contemporânea de Educação, v. 4, n.8, p.301-318, 2012.

SULLIVAN, Patricia M. Violence exposure among children with disabilities. Clinical Child and Family Psychology Review, v.12, n.2, p.196-216. 2009.

\section{Notas}

\footnotetext{
${ }^{1}$ Altera a Lei $\mathrm{n}^{0}$ 13.979, de 6 de fevereiro de 2020.

2 Os dados obtidos dos relatórios das secretarias municipais de assistência social dos municípios em estudo foram solicitados baseado na Lei nํ⒓527/2011- Lei Geral de Acesso a Informações Públicas.

${ }^{3}$ A proposta da elaboração do Programa bolsa Família é instituído no governo de Luiz Inácio Lula da Silva (2003-2006) pelo Decreto n 5.209/2004, que regulamentou a Lei nº 10.836/2004.
} 